\title{
Design Method and Cost-Benefit Analysis of Hybrid Fiber Used in Asphalt Concrete
}

\author{
Haiwei Zhang, ${ }^{1}$ Peiwen Hao, ${ }^{1}$ Yuan Pang, ${ }^{1}$ and Aaron D. Mwanza ${ }^{2}$ \\ ${ }^{1}$ School of Highway, Chang'an University, Xi'an, Shaanxi 710064, China \\ ${ }^{2}$ China Civil Engineering Construction Corporation, Fuzhou Survey and Design Institute, Fuzhou, Fujian 350013, China \\ Correspondence should be addressed to Haiwei Zhang; zhw806098331@163.com
}

Received 11 June 2016; Accepted 25 August 2016

Academic Editor: Belal F. Yousif

Copyright (c) 2016 Haiwei Zhang et al. This is an open access article distributed under the Creative Commons Attribution License, which permits unrestricted use, distribution, and reproduction in any medium, provided the original work is properly cited.

\begin{abstract}
Fiber, as an additive, can improve the performance of asphalt concrete and be widely studied, but only a few works have been done for hybrid fiber. This paper presents a new and convenient method to design hybrid fiber and verifies hybrid fiber's superiority in asphalt pavement engineering. Firstly, this paper expounds the design method used as its applied example with the hybrid fiber composed of lignin, polyester, and polypropylene fibers. In this method, a direct shear device (DSD) is used to measure the shear damage energy density (SDED) of hybrid fiber modified asphalts, and range and variance statistical analysis are applied to determine the composition proportion of hybrid fiber. Then, the engineering property of hybrid fiber reinforced asphalt concrete (AC-13) is investigated. Finally, a cost-benefit model is developed to analyze the advantage of hybrid fiber compared to single fibers. The results show that the design method employed in this paper can offer a beneficial reference. A combination of $1.8 \%$ of lignin fiber and $2.4 \%$ of polyester fiber plus 3.0\% polypropylene fiber presented the best reinforcement of the hybrid fiber. The cost-benefit model verifies that the hybrid fiber can bring about comprehensive pavement performance and good economy.
\end{abstract}

\section{Introduction}

Asphalt pavement has many advantages, such as low noise, good skid-resistance and comfort, easy maintenance, and recyclability, while it is subjected to rutting and cracking under the effects of repeated vehicle loading and climatic variations $[1,2]$. Therefore, additives such as fibers, polymers, and rubber are used in asphalt mixtures to reduce cracking and rutting phenomena in asphalt pavement [3]. A good deal of research shows that fibers can be used as an effective additive in asphalt concrete to improve pavement performance, including dynamic modulus, resistance to rutting, resistance to low-temperature cracking, and antireflective cracking as well as moisture susceptibility [4-8]. There is no doubt that these benefits contribute to extending the service life of asphalt pavement.

So far, three common fibers used in asphalt pavement engineering are lignin fiber, polyester fiber, and polypropylene (PP) fiber $[9,10]$. However, the role of lignin fiber in improving the engineering performance of asphalt concretes is less obvious [11]. The improving effect of polymer fiber and PP fiber is very significant but over-high price limits their application [12]. Against that background, hybrid fiber formed by the mixing of different fibers may be a key to solving the above problem. Hybrid fiber is defined as the fiber containing two or three or more kinds of single fiber. Although hybrid fiber is widely used in cement concrete material [13], it is really a new concept applied in asphalt concrete. The good news is that it has gradually attracted the attention of the researchers, and some achievements have been made about this new material. For example, Wu et al. [14] and Yue and $\mathrm{Wu}$ [15] investigated the engineering performance of hybrid fiber which consisted of cellulose fiber and polyester fiber, finding that the pavement performances of asphalt mixture containing hybrid fiber can be improved and the enhancement of hybrid fiber was more significant than the single cellulous fiber. Abtahi et al. [16] introduced the hybrid reinforcement of AC mixture using PP and glass fibers and drew the conclusion that a combination of $0.1 \%$ (by weight of aggregate) of glass fiber plus 6\% (by weight of bitumen) of PP fiber presented the best hybrid reinforcement based on Marshall Stability test. Vadood et al. 


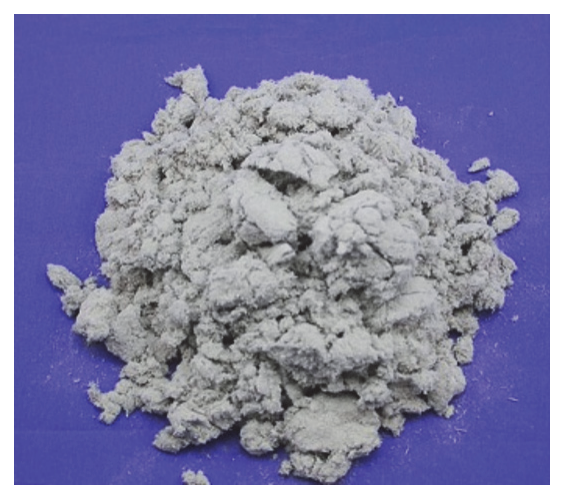

(a)

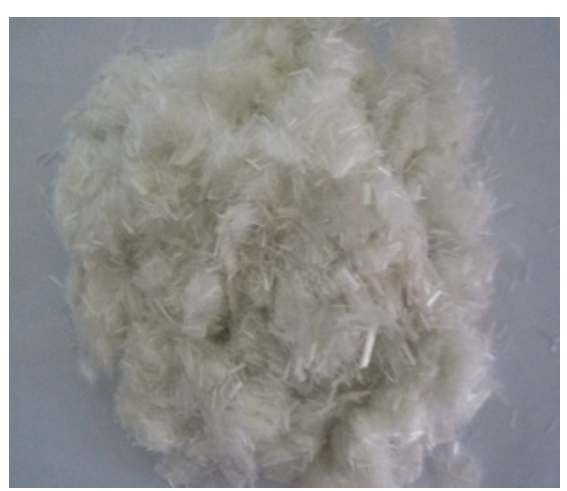

(b)

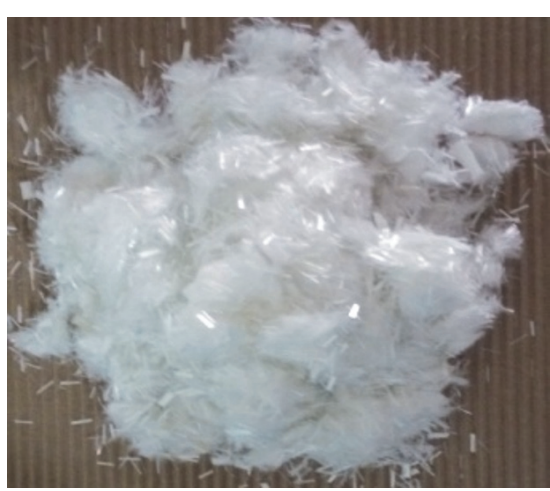

(c)

FIGURE 1: Fibers: (a) lignin fiber; (b) polyester fiber; (c) polypropylene fiber.

TABLE 1: Physical properties of the asphalt.

\begin{tabular}{lcc}
\hline Items & Testing method & Tested value \\
\hline Penetration at $25^{\circ} \mathrm{C}, 100 \mathrm{~g}(0.1 \mathrm{~mm})$ & ASTM D-5 & 71.2 \\
Softening point $\left({ }^{\circ} \mathrm{C}\right)$ & ASTM D-36 & 47.5 \\
Ductility at $15^{\circ} \mathrm{C}(\mathrm{cm})$ & ASTM D-113 & 104 \\
Specific gravity at $25^{\circ} \mathrm{C}$ & ASTM D-70 & 1.013 \\
\hline
\end{tabular}

[17] investigated the resilient modulus of HMA reinforced by hybrid fiber which comprised PP and polyester fibers and developed an artificial neural network-genetic algorithm model to predict this resilient modulus.

Through analyzing the current research, it is known that hybrid fiber has considerable potential to be used in the asphalt concrete. However, the work of design asphalt concrete reinforced by hybrid fiber is time-consuming and requires lots of trials of asphalt mixture experiment. Especially for the hybrid fiber which is constitutive of three kinds of single fibers, test task will increase dramatically due to more influencing factors being involved. In addition, economic performance of hybrid fiber is not clear, which also limits its application in asphalt pavement engineering. Thus, this paper aims to put forward a convenient method to design hybrid fiber modified asphalt concrete and verify the applicability of hybrid fiber in asphalt pavement engineering.

\section{Raw Materials}

2.1. Asphalt. A virgin asphalt binder (A-70) is selected in this study and its properties are detailed in Table 1.

2.2. Fibers. The hybrid fibers used in this study are composed of different proportions of lignin, polyester, and PP fibers, as shown in Figure 1. The basic physical properties of the three fibers are listed in Table 2 (provided by manufacturers).

2.3. Aggregates. The coarse aggregates are made from limestone with a maximal size of $16 \mathrm{~mm}$ and a density of $2.752 \mathrm{~g} / \mathrm{cm}^{3}$. The fine aggregates are machine-made sand whose density is $2.715 \mathrm{~g} / \mathrm{cm}^{3}$. Mineral filler is also made from limestone with a passing range $(0.075 \mathrm{~mm})$ of $90.3 \%$ by weight, and its density is $2.724 \mathrm{~g} / \mathrm{cm}^{3}$. The gradation of

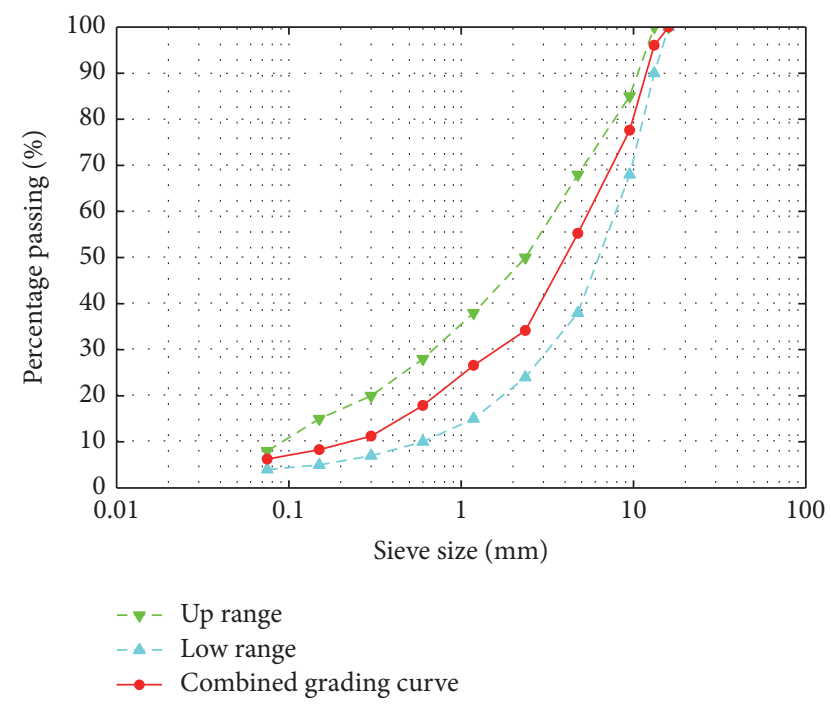

Figure 2: Aggregate gradation.

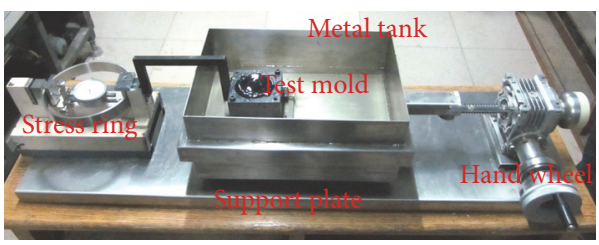

Figure 3: The direct shear device (DSD).

mixed aggregate which is selected in accordance with the specification [18] is presented in Figure 2.

\section{Design of the Hybrid Fiber}

Direct shear test and orthogonal experimental design are combined, carried out in this paper as a method to design the composition of hybrid fiber and its optimum dosage in asphalt.

3.1. Test Device. The device used in the direct shear test is shown in Figures 3 and 4. The device consists of a support 
TABLE 2: Physical properties of fibers.

\begin{tabular}{lccc}
\hline Items & Lignin fiber & Polyester fiber & Polypropylene fiber \\
\hline Diameter $(\mu \mathrm{m})$ & 42 & 20 & 22 \\
Length $(\mathrm{mm})$ & 1.2 & 6.0 & 8.0 \\
Specific gravity & 1.32 & 1.46 & 0.95 \\
Tensile strength $(\mathrm{MPa})$ & $\mathrm{N} / \mathrm{A}$ & 517 & 440 \\
Elongation at break $(\%)$ & 18 & 33 & 24 \\
Oil absorption rate $(\%)$ & 5.68 & 3.88 & 2.85 \\
Melting point $\left({ }^{\circ} \mathrm{C}\right)$ & 255 & 249 & 166 \\
\hline
\end{tabular}

TABLE 3: Orthogonal experimental design and experimental results.

\begin{tabular}{|c|c|c|c|c|c|c|c|}
\hline \multirow{2}{*}{ Group number } & \multicolumn{3}{|c|}{ Factors and its level } & \multirow{2}{*}{ Proportions (A : B : C : basic asphalt) } & \multicolumn{3}{|c|}{$\mathrm{SDED}$ results $/\left(\mathrm{KJ} / \mathrm{m}^{3}\right)$} \\
\hline & A dosage $/ \%$ & B dosage/\% & C dosage $/ \%$ & & Parallel 1 & Parallel 2 & Average \\
\hline $1 \#$ & 1.8 & 1.8 & 1.8 & $1.8: 1.8: 1.8: 100$ & 5.8 & 5.2 & 5.5 \\
\hline 2\# & 1.8 & 2.4 & 2.4 & $1.8: 2.4: 2.4: 100$ & 45.4 & 42.1 & 43.7 \\
\hline 3\# & 1.8 & 3.0 & 3.0 & $1.8: 3.0: 3.0: 100$ & 31.3 & 34.5 & 32.9 \\
\hline $4 \#$ & 2.4 & 1.8 & 2.4 & $2.4: 1.8: 2.4: 100$ & 12.7 & 10.9 & 11.8 \\
\hline $5 \#$ & 2.4 & 2.4 & 3.0 & $2.4: 2.4: 3.0: 100$ & 25.5 & 24.3 & 24.9 \\
\hline $6 \#$ & 2.4 & 3.0 & 1.8 & $2.4: 3.0: 1.8: 100$ & 11.2 & 11.7 & 11.5 \\
\hline $7 \#$ & 3.0 & 1.8 & 3.0 & $3.0: 1.8: 3.0: 100$ & 22.4 & 21.3 & 21.9 \\
\hline $8 \#$ & 3.0 & 2.4 & 1.8 & $3.0: 2.4: 1.8: 100$ & 9.5 & 11.9 & 10.7 \\
\hline 9\# & 3.0 & 3.0 & 2.4 & $3.0: 3.0: 2.4: 100$ & 6.7 & 7.2 & 6.9 \\
\hline
\end{tabular}

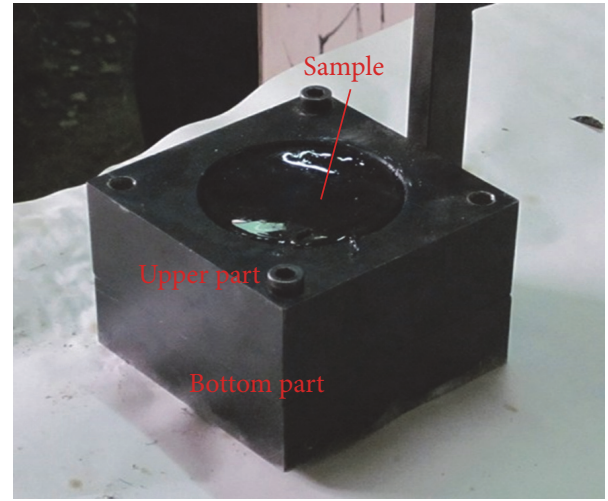

Figure 4: The test mold.

plate (used for supporting other parts of the device), a metal tank (used for ensuring the sample in the specified temperature during test and fixing the bottom part of the test mold), a hand wheel (used for applying load), a stress ring (used for measuring the shear stress that sample bore), and a test mold consisting of upper part and bottom part (used for forming and fixing sample). In the test, the metal tank and the bottom part of the test mold move at a constant speed by rotating the wheel manually, but the upper part of the test mold cannot be moved because of the impeding forces from the stress ring. That means the upper and bottom mold slide relatively at a constant speed and the asphalt sample will bear a shearing force. The shear resistance of the sample is reflected by the microscopic deformation of the stress ring that is connected with the upper mold by one steel linkage. Dial indicator measures the deformation of stress ring.
3.2. Orthogonal Experimental Design. The effect of hybrid fiber on asphalt mixtures mainly depends on its effect on the asphalt. So, the hybrid modified asphalt being composed of asphalt and fibers is regarded as experiment object in the direct shear test to determine the optimum composition of hybrid fiber and its optimum dosage in asphalt. When lignin fiber, polyester fiber, and PP fiber are applied independently of each other in the asphalt concrete, the recommended content is within the range of $0.3 \% \sim 0.5 \%$ by weight of mix generally $[19,20]$. Because asphalt content of the asphalt concrete is usually about $5 \%$, each fiber can have three levels of dosage which are $1.8 \%, 2.4 \%$, and $3.0 \%$ by weight of the asphalt when they are used jointly as hybrid fiber in this study. There will be 27 kinds of hybrid fibers under different combinations of three types of fiber. It is obvious that the experiment is too heavy for a designer pursuing the optimal combination of hybrid fiber among 27 groups tests.

In this research, there are three influencing factors, which are lignin fiber (A), polyester fiber (B), and polypropylene fiber (C), with each one having three measurement levels for comparison. Due to various factors influencing testing results, orthogonal experimental design is adopted to reduce testing time and simplify statistical data analysis. The orthogonal diagram of three factors and three levels is shown in Table 3. There are totally 9 combinations in Table 3 and two parallel tests were carried out for each test combination.

3.3. Test Procedure. The direct shear test is conducted with different hybrid modified asphalt using the direct shear device (DSD). Before the test, the hybrid fiber modified asphalt samples are prepared. Firstly, 9 kinds of hybrid fibers are compound according to the dosage of lignin, polyester, 


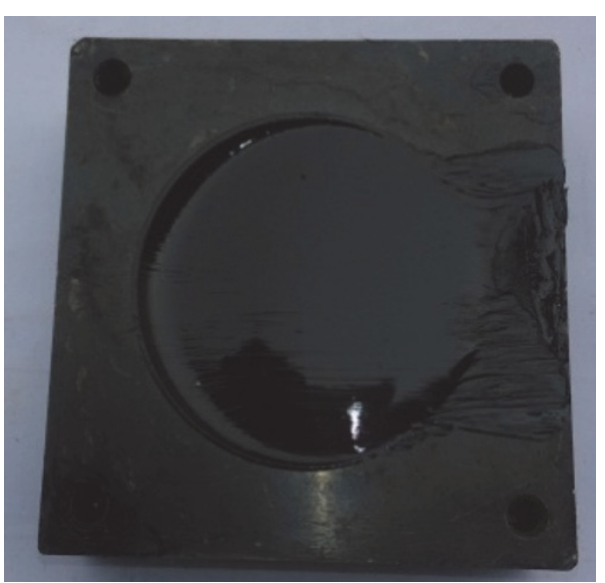

(a)

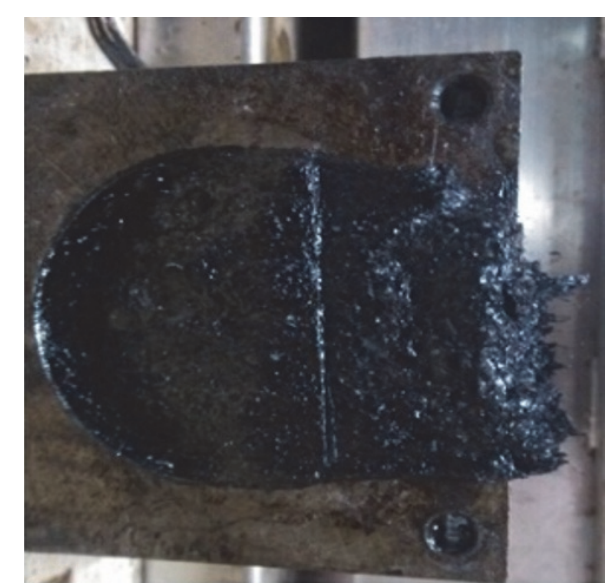

(b)

FIGURE 5: Failure mode of samples: (a) pure asphalt; (b) hybrid fiber modified asphalt.

and PP fibers shown in Table 3. Then $180 \mathrm{~g}$ virgin asphalt is heated to $155 \pm 5^{\circ} \mathrm{C}$ and the hybrid fiber is added into the asphalt slowly. In order to secure the uniformity of hybrid fiber distribution, it would take at least $30 \mathrm{~min}$ to mix the hybrid fiber with the asphalt during the process of adding fibers. In the end, the prepared hybrid fiber modified asphalt is poured into the metal test mold with a hollow cylinder $(\phi 60 \mathrm{~mm} \times H 70 \mathrm{~mm})$. It usually needs at least 3 hours to drop to room temperature and form shape for the samples.

The test mold containing sample is placed in the water bath for heat preservation at the temperature of $20^{\circ} \mathrm{C}$ for 3 hours, so that the temperature of the sample can achieve the set value and the inside and outside temperature of the sample are the same. The temperature of the water in the metal tank of the device is also at $20 \pm 0.5^{\circ} \mathrm{C}$ to keep the sample temperature constant during the shear process. After the test mold is fixed to the metal tank, the metal tank location is adjusted though rotating the wheel to ensure close contact of the upper test mold to the stress ring. The sample is sheared at a constant speed of $0.12 \mathrm{~mm} / \mathrm{s}$ when the wheel is rotated at a circle per 5 seconds. At the same time, the deformation of stress ring is read off on the dial indicator and the shear stress can be got through the transformation of dial indicator data.

3.4. Failure Characteristics of Samples. The failed samples are shown in Figure 5. Some differences are observed between the pure asphalt sample and the hybrid fiber modified asphalt samples after shear tests. Figure 5 shows that the failure surface of hybrid fiber modified asphalt is rougher and its extension deformation is bigger in comparison with the pure asphalt sample, which is an intuitive evidence of interwoven distribution of the hybrid fiber and the reinforcement effect of hybrid fiber in the asphalt.

To describe the damage process of samples quantitatively, the shear stress-strain curves of hybrid modified asphalt experiment groups and pure asphalt are drawn as shown in Figure 6. In Figure 6 it is clear that the curves can be divided into two stages for both kinds of samples. In the first stage, the shear stress value $\sigma$ increases with the increasing of the

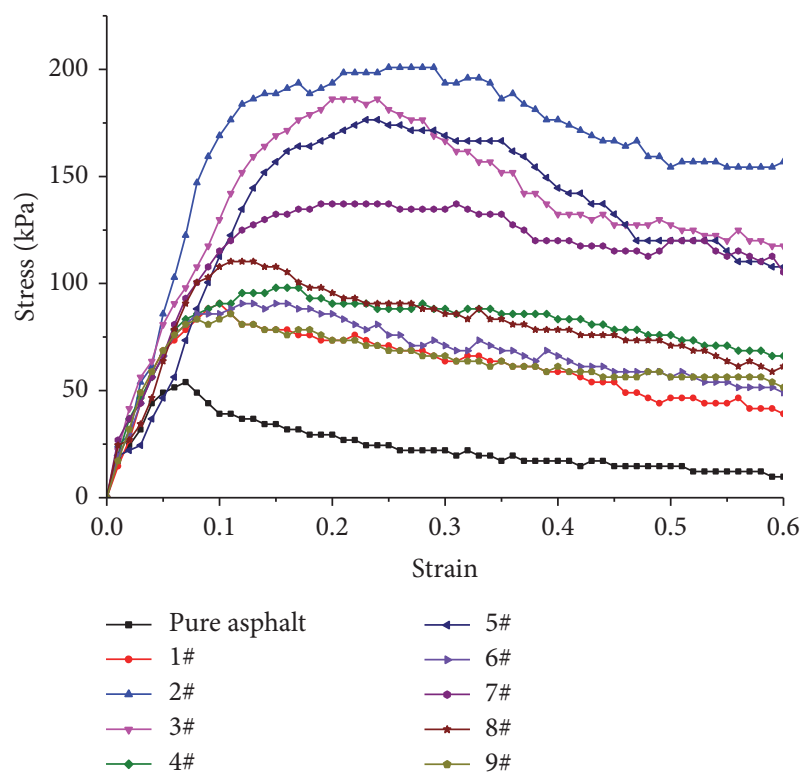

FIGURE 6: Shear stress-strain curves of samples.

shear strain value until the peak value of $\sigma$ is reached. In the second stage when samples turn in the state of failure, for the pure asphalt sample, $\sigma$ declines rapidly as the strain value continues to increase. However, $\sigma$ for the hybrid modified asphalt samples show a slow decline and a stable transition. In the end of the test process, $\sigma$ for the hybrid modified asphalt samples are higher rather than close to zero for the pure asphalt sample. The reason for this phenomenon is the tacky property of PP fiber and the reinforcement effect of the fibers which increase the cohesive force of asphalt material. In addition, there are some singularities in the second stage of the curve so that it looks not so smooth. It might be attributed to two reasons: (a) the fibers could not be in incompletely uniform distribution in the asphalt; (b) manual loading is difficult to ensure completely constant shear speed, which needs to be improved in the future. However, the overall trend 
of the curves and the test result are not obviously affected by these deficiencies.

3.5. Shear Damage Energy Density. The deformation and destruction of these samples induced by the shearing force in the test can be explained using energy dissipation. During the shear test, the energy dissipation before the shearing force reaches the maximum value indicates the ability to resist shear damage of the samples. Therefore, the index called the shear damage energy density (SDED) is introduced in this study to describe the energy dissipation, which is similar to the concept of fracture energy density [21] but describes the shear resistance of material. SDED is calculated from the area formed by the shear stress line and the shear strain line $(x-$ axis) as follows:

$$
\mathrm{SDED}=\int_{0}^{\varepsilon_{f}} \sigma(\varepsilon) d \varepsilon
$$

where SDED is the shear damage energy density, $\mathrm{kJ} / \mathrm{m}^{3} ; \sigma(\varepsilon)$ is the shear stress of samples when the strain value is $\varepsilon, \mathrm{kPa}$; $\varepsilon_{f}$ is the failure strain of samples which is corresponding to the shear strength $\sigma_{\max }$.

3.6. Range and Variance Analysis. The experimental results are shown in Table 3. It is observed that different hybrid fiber modified asphalts produce very different shear resistance performance and the maximum value of $\operatorname{SDED}\left(43.7 \mathrm{KJ} / \mathrm{m}^{3}\right)$ is nearly eight times the minimum value $\left(5.5 \mathrm{KJ} / \mathrm{m}^{3}\right)$. Therefore, a proper combination of three single fibers is very important and necessary. In addition, it indicates the direct shear test can distinguish the shear performance of different hybrid fiber modified asphalts.

The range analysis of SDED is carried out to assess the effect of the three factors on the shear resistance of the samples and select the optimal combination of the three kinds of fiber constituting hybrid fiber. The results of SDED for each level of influencing factor $K_{i}$ are given in Table 4 . The $K_{i}$ results show that the SDED increases as the lignin fiber dosage decreases and the PP fibers dosage increases, while the SDED can firstly increase and then decrease with the polyester fiber dosage increasing. In order to obtain the maximum SDED, the optimal dosage of lignin fiber, polyester fiber, and PP fibers in the hybrid fiber modified asphalt is $1.8 \%, 2.4 \%$, and $3.0 \%$, respectively, which means that the optimum dosage of hybrid fiber in asphalt is $7.2 \%$ and the composition ratio of hybrid fiber is $3: 4: 5$ (lignin fiber, polyester fiber, and PP fibers). However, this optimized hybrid fiber testing program is not included in the orthogonal diagram. A complementary test which is about the optimized hybrid fiber was conducted and its SDED is $48.2 \mathrm{KJ} / \mathrm{m}^{3}$ which is greater than any group in the orthogonal diagram. This demonstrates that the process to determine hybrid fiber composition based on orthogonal experimental design is reasonable.

The impact range $R$ is calculated in Table 4 to evaluate the effect of different factors on the SDED. A greater range reflects a greater influence on SDED. So, PP fiber dosage has the greatest effect on the SDED, lignin fiber dosage is next,
TABLE 4: Range analysis for SDED.

\begin{tabular}{lccc}
\hline Testing levels & A dosage & B dosage & C dosage \\
\hline$K_{1}$ & 27.4 & 13.1 & 9.2 \\
$K_{2}$ & 16.1 & 26.5 & 20.8 \\
$K_{3}$ & 13.2 & 17.1 & 26.6 \\
Impact range $R$ & 14.2 & 13.4 & 17.3 \\
\hline
\end{tabular}

and polyester fiber dosage is the least. Furthermore, the range of the factor of PP fiber dosage is significantly larger than that of the other two factors. This indicates that PP fiber dosage is the key parameter in the design of this kind of hybrid fiber.

Analysis of variance (ANOVA) is also conducted to verify the above range analysis because range analysis is difficult to consider the effect of experiment error and evaluate whether the influence of various factors on the SDED is statistically significant or not. In this paper, ANOVA is performed using the software of Statistical Product and Service Solutions (SPSS) and the results are presented in Table 5. It is clear that the significance probabilities of the $F$ values for the three factors are all below 0.05, indicating prominent impacts of the three factors on the SDED within 95\% confidence level. Moreover, PP fiber dosage has the most significant levels for SDED, followed by lignin fiber and polyester fiber through comparing the $F$ value. The significant ranking of different factors fits with the range analysis, which suggests that the range analysis is reasonable.

\section{Engineering Performances of Hybrid Fiber Reinforced Asphalt Concrete}

The optimum asphalt content (OAC), fiber dosage and volume of air voids (VV) of base asphalt concrete (AC), lignin fiber reinforced asphalt concrete (LFRAC), polyester fiber reinforced asphalt concrete (PFRAC), polypropylene fiber reinforced asphalt concrete (PPFRAC), and hybrid fiber reinforced asphalt concrete (HFRAC) are determined using the Marshall Design procedure [18], detailed in Table 6. Then their engineering performances are evaluated based on the laboratory test. The test methods are briefly described below.

4.1. Experimental Methods. Rutting resistance of FRAC was measured by wheel tracking test according to T0719 (JTJ E202011) [22]. The square slab specimens $(300 \mathrm{~mm} \times 300 \mathrm{~mm}$ $\times 50 \mathrm{~mm}$ ) were loaded with a special solid rubber tire whose contact pressure is $0.7 \mathrm{MPa}$ in a constant temperature chamber at the temperature of $60^{\circ} \mathrm{C}$. The tire wheeled for 1 hour at the speed of $42 \pm 1$ cycles/min during the test process. Rutting depths were measured and dynamic stability (DS) could be expressed as follows:

$$
\mathrm{DS}=\frac{15 \times 42}{d_{60}-d_{45}}=\frac{630}{d_{60}-d_{45}},
$$

where $d_{45}$ and $d_{60}$ are the rutting depth at $45 \mathrm{~min}$ and $60 \mathrm{~min}$, respectively.

The low-temperature bending test was used to measure low-temperature crack resistance of FRAC according to 
TABLE 5: Variance analysis for SDED.

\begin{tabular}{|c|c|c|c|c|c|}
\hline Source & Type III sum of squares & Degrees of freedom & Mean square & $F$ value & $\begin{array}{l}\text { Sig. } \\
\end{array}$ \\
\hline A & 677.743 & 2 & 338.872 & 6.857 & 0.012 \\
\hline B & 566.770 & 2 & 283.385 & 5.734 & 0.020 \\
\hline $\mathrm{C}$ & 936.143 & 2 & 468.072 & 9.471 & 0.004 \\
\hline Error & 543.263 & 11 & 49.420 & & \\
\hline
\end{tabular}

TABLE 6: Physical properties of different asphalt concretes.

\begin{tabular}{lccc}
\hline Type of mixtures & Fiber dosage/\% & OAC/\% & VV $/ \%$ \\
\hline AC & N/A & 5.0 & 4.1 \\
LFRAC & 7.2 & 5.3 & 4.2 \\
PFRAC & 7.2 & 5.2 & 4.1 \\
PPFRAC & 7.2 & 5.1 & 4.2 \\
HFRAC & 7.2 & 5.2 & 4.1 \\
\hline
\end{tabular}

T0715 (JTJ E20-2011) [22]. The loading was applied on the middle of the beam specimens $(250 \mathrm{~mm} \times 30 \mathrm{~mm} \times 35 \mathrm{~mm})$ with a loading rate of $50 \mathrm{~mm} / \mathrm{min}$ in a constant temperature chamber at $-10^{\circ} \mathrm{C}$. The failure strain $\varepsilon_{\mathrm{B}}$ is defined as the maximum tensile strain on the bottom of the beam when the load reaches its peak. It is calculated to characterize the low-temperature cracking resistance of asphalt concrete as follows:

$$
\varepsilon_{\mathrm{B}}=\frac{6 h d}{L^{2}}
$$

where $h$ is the height of the cross section of the beam sample, $\mathrm{mm} ; d$ is the midspan deflection at the specimen failure, $\mathrm{mm}$; $L$ is the span length of the beam, $L=20 \mathrm{~mm}$.

The moisture susceptibility of different FRAC was measured by freeze-thaw split test in this paper. According to T0729 (JTJ E20-2011) [22], standard Marshall specimens $(\phi 101.6 \mathrm{~mm} \times H 63.5 \mathrm{~mm})$ were prepared and divided into two groups. The first group samples were placed in a freezer at $-18 \pm 2^{\circ} \mathrm{C}$ for $16 \mathrm{~h}$, then removed to a water bath at $60 \pm 1^{\circ} \mathrm{C}$ for $24 \mathrm{~h}$, and finally placed in a water bath at $25 \pm 0.5^{\circ} \mathrm{C}$ for $2 \mathrm{~h}$. The second group samples were just placed in a water bath at $25 \pm 0.5^{\circ} \mathrm{C}$ for $2 \mathrm{~h}$. Then the indirect tensile strength of the two group samples was tested with the loading rate of $50 \mathrm{~mm} / \mathrm{min}$. Consequently, the tensile strength ratio (TSR) evaluating the water damage resistance is calculated as follows:

$$
\mathrm{TSR}=\frac{R_{T 1}}{R_{T 2}} \times 100,
$$

where $R_{T 1}$ is the tensile strength of samples after freeze-thaw cycle, $\mathrm{MPa} ; R_{T 2}$ is the tensile strength of the fresh samples, $\mathrm{MPa}$.

4.2. Experimental Results. The results of wheel tracking test of different asphalt concretes are shown in Figure 7. It is clear that high-temperature rutting resistance of asphalt concrete is improved by adding fibers. The dynamic stabilities (DS) of hybrid fiber, lignin fiber, polyester fiber, and PP fiber reinforced asphalt concrete are 174\%, 40\%, 113\%, and 191\% higher than that of the base asphalt concrete, which shows

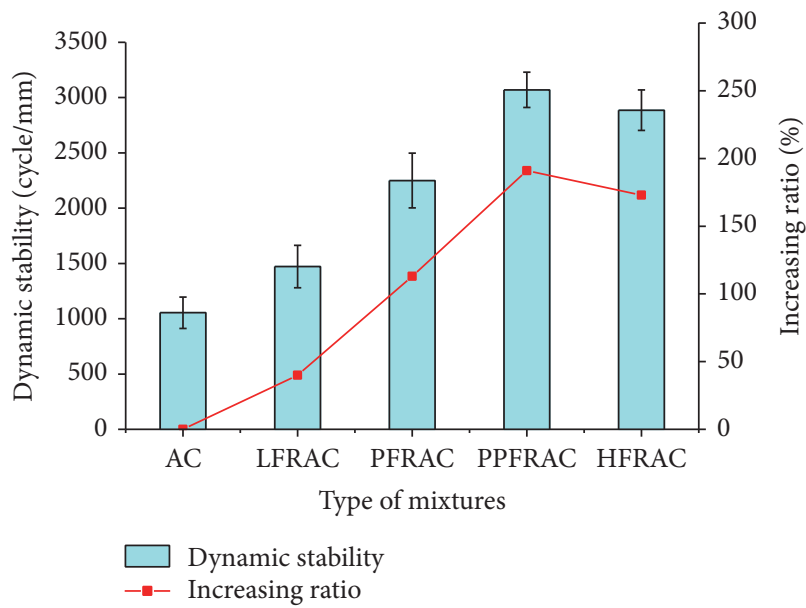

FIgURE 7: Results of the wheel rutting test.

that the improving effect of the hybrid fiber is commensurate with that of PP fiber and is far more than that of the lignin fiber and polyester fiber. It also indicates that the hybrid fiber can fully exert advantage of PP fiber in the respect of hightemperature performance and make up for the lacks of lignin fiber and polyester fiber.

The results of low-temperature bending failure strain of different asphalt concretes are detailed in Figure 8. The failure strains of hybrid fiber, lignin fiber, polyester fiber, and PP fiber reinforced asphalt concrete are 36\%, 20\%, 44\%, and 25\% higher than that of the base asphalt concrete. It shows that the low-temperature cracking resistance is improved by adding fibers in asphalt concrete. Meanwhile, hybrid fiber obtains a higher increasing ratio than the lignin fiber and PP fiber, but slightly lower than that of polyester fiber.

The results of freeze-thaw split test of different asphalt concretes are presented in Figure 9. It can be found that indirect tensile strength of the fiber reinforced asphalt concretes is higher than that of the base asphalt concrete for either fresh samples or samples after freeze-thaw cycle. The results prove the reinforcing effect of fibers in the asphalt mixture during the process of sustaining tension. Furthermore, the TSR of the base asphalt concrete, HFRAC, LFRAC, PFRAC, and PPFRAC are $80.0 \%, 89.2 \%, 83.5 \%, 87.5 \%$, and $87.1 \%$, respectively. This result indicates that fibers, especially for the hybrid fiber, can improve the moisture susceptibility of asphalt concretes.

\section{Cost-Benefit Analysis}

5.1. Evaluation Model. The application of the hybrid fiber in engineering is determined by its cost-benefit instead of 


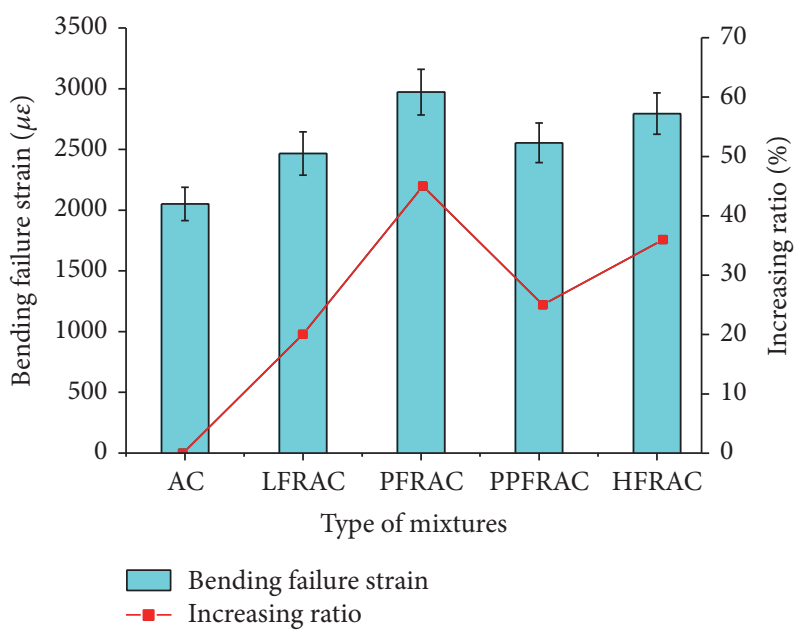

Figure 8: Results of the low-temperature bending test.

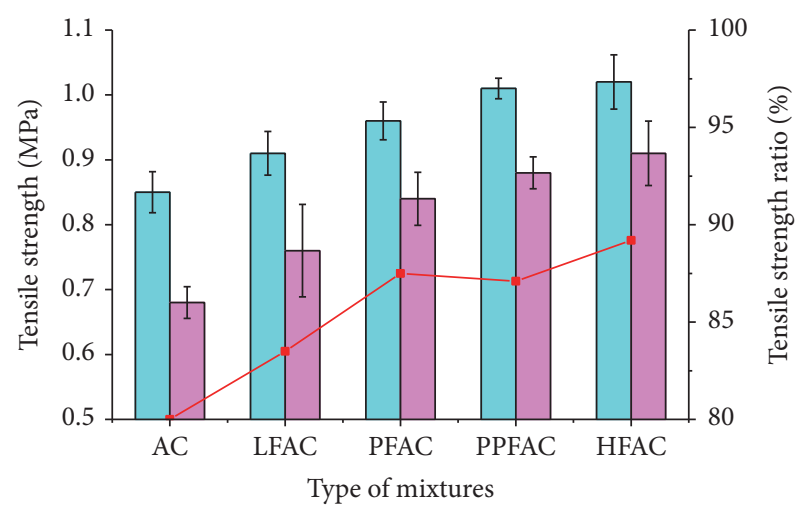

The indirect tensile strength of the fresh samples

The indirect tensile strength of samples after freeze-thaw cycle - - Tensile strength ratio

FIGURE 9: Results of the freezing-thaw cycling test.

engineering performance alone. Therefore, an analysis model is developed in this paper to compare the cost-benefit of hybrid fiber and three single fibers, and the equations of the model could be expressed as follows:

$$
\begin{aligned}
V & =\frac{F}{C}, \\
F & =\sum_{i} F_{i} W_{i}, \\
F_{i} & =\frac{Y_{i}^{m}-Y_{i}^{b}}{\operatorname{Max}\left\{Y_{i}^{1}, Y_{i}^{2}, Y_{i}^{3}, Y_{i}^{4}\right\}-Y_{i}^{b}},
\end{aligned}
$$

where $V$ is the value coefficient which is defined as the quantitative index to evaluate the cost-benefit of various fibers; $F$ is the comprehensive engineering performance promotion coefficient of FRAC compared to base asphalt concrete; $C$ is the additional cost for FRAC compared to base asphalt concrete; $F_{i}$ is the individual engineering performance promotion coefficient of FRAC. High-temperature
TABLE 7: Engineering performance promotion coefficient of different asphalt mixtures.

\begin{tabular}{lcccc}
\hline Type of mixtures & $F_{1}(\mathrm{DS})$ & $F_{2}\left(\varepsilon_{\mathrm{B}}\right)$ & $F_{3}(\mathrm{TRS})$ & $F$ \\
\hline LFRAC & 0.207 & 0.452 & 0.382 & 0.347 \\
PFRAC & 0.593 & 1.000 & 0.814 & 0.802 \\
PPFRAC & 1.000 & 0.546 & 0.774 & 0.773 \\
HFRAC & 0.909 & 0.808 & 1.000 & 0.906 \\
\hline
\end{tabular}

rutting resistance, low-temperature cracking resistance, and water damage resistance of FRAC are mainly tested in this paper, so the value of $i$ is the numbers 1,2 , and 3 to represent them, respectively. $W_{i}$ is the weight coefficient of $F_{i}$, which is determined according to specific conditions. For example, in the region where rut is very likely to happen, $W_{1}$ should be greater than $W_{2}$ and $W_{3}$ to highlight the importance of $F_{1} . Y_{i}^{m}$ is the individual test index of the modified asphalt concrete whose number is $m$. There are four kinds of FRAC involved in this paper, so the value of $m$ is the numbers 1,2,3, and 4 to represent them, respectively. $Y_{i}^{b}$ is the individual test index of the base asphalt concrete.

5.2. Calculation and Comparison. Based on the developed evaluation model and the engineering performance test results, the individual engineering performance promotion coefficient $F_{i}$ of different FRAC can be calculated, as shown in Table 7. The lignin fiber reinforced asphalt concrete is used as an example here to illustrate how its $F_{i}$ is calculated. The values of dynamic stability (cycles/min) of the base asphalt concrete, LFRAC, PFRAC, PPFRAC, and HFRAC are 1055, $1472,2250,3070$, and 2886, respectively. The values of failure strain $(\mu \varepsilon)$ of the above five kinds of asphalt mixtures are 2051, $2467,2972,2654$, and 2795, respectively. The tensile strength ratios of the above five kinds of asphalt mixtures are $80.0 \%$, $83.5 \%, 87.5 \%, 87.1 \%$, and $89.2 \%$, respectively. So, $F_{i}$ of lignin fiber reinforced asphalt concrete can be calculated as follows:

$$
\begin{aligned}
F_{1} & =\frac{1472-1055}{\operatorname{Max}\{1472,2250,3070,2886\}-1055}=0.207, \\
F_{2} & =\frac{2467-2051}{\operatorname{Max}\{2467,2972,2654,2795\}-2051}=0.452, \\
F_{3} & =\frac{83.5 \%-80.0 \%}{\operatorname{Max}\{83.5 \%, 87.5 \%, 87.1 \%, 89.2 \%\}-80.0 \%} \\
& =0.382 .
\end{aligned}
$$

In the process of calculating $F$, the values of $W_{1}, W_{2}$, and $W_{3}$ are usually different when the various road performance requirement degrees are different in a particular region. However, $W_{1}, W_{2}$, and $W_{3}$ are all equal to $1 / 3$ in this paper to make the results more representative, which means that the importance degrees of the resistance to high-temperature rutting, low-temperature cracking, and water damage are the same. Therefore lignin fiber reinforced asphalt concrete can be calculated as follows:

$$
F=\frac{F_{1}+F_{2}+F_{3}}{3}=0.409 .
$$


TABLE 8: Additional cost for different fiber modified asphalt concretes (one ton).

\begin{tabular}{|c|c|c|c|c|c|c|c|}
\hline $\begin{array}{l}\text { Type of } \\
\text { mixtures }\end{array}$ & $\begin{array}{c}\text { Fiber } \\
\text { amounts/kg }\end{array}$ & $\begin{array}{c}\text { Fiber } \\
\text { expense/yuan }\end{array}$ & $\begin{array}{c}\text { Increased asphalt } \\
\text { content } / \mathrm{kg}\end{array}$ & $\begin{array}{c}\text { Increased asphalt } \\
\text { expense/yuan }\end{array}$ & $\begin{array}{c}\text { Increased fuel } \\
\text { amount } / \mathrm{kg}\end{array}$ & $\begin{array}{l}\text { Increased fuel } \\
\text { expense/yuan }\end{array}$ & $\begin{array}{c}\text { Additional cost/one } \\
\text { hundred yuan }\end{array}$ \\
\hline LFRAC & 3.61 & 10.8 & 2.53 & 10.13 & 0.5 & 1.5 & 0.225 \\
\hline PFRAC & 3.55 & 42.6 & 1.64 & 6.54 & 0.5 & 1.5 & 0.506 \\
\hline PPFRAC & 3.48 & 45.3 & 0.74 & 2.95 & 0.5 & 1.5 & 0.497 \\
\hline HFRAC & 3.55 & 36.1 & 1.64 & 6.54 & 0.5 & 1.5 & 0.441 \\
\hline
\end{tabular}

TABle 9: Value coefficient for different fiber modified asphalt mixtures.

\begin{tabular}{lc}
\hline Type of mixtures & Value coefficient for one hundred yuan \\
\hline LFRAC & 1.43 \\
PFRAC & 1.58 \\
PPFRAC & 1.55 \\
HFRAC & 2.03 \\
\hline
\end{tabular}

Considering the expense in construction of asphalt concrete, additional cost of each FRAC compared to base asphalt concrete mainly includes fiber material expense, increased asphalt material expense, and increased fuel expense. Referring to the market price in China, the prices of base asphalt, lignin fiber, polyester fiber, and polypropylene fiber are $4000 \mathrm{RMB} ¥ /$ ton, $3500 \mathrm{RMB} ¥ /$ ton, $12000 \mathrm{RMB} ¥$ ton, and $13000 \mathrm{RMB} ¥ /$ ton, respectively. In addition, the mixing temperature is usually $150 \sim 155^{\circ} \mathrm{C}$ for base asphalt mixture and $160 \sim 165^{\circ} \mathrm{C}$ for FRAC. So, base asphalt concrete and fiber reinforced asphalt concretes have different energy consumption in the process of production, which means that one ton of fiber reinforced asphalt mixture needs more $0.5 \mathrm{~kg}$ fuel oil with about $3000 \mathrm{RMB} ¥ /$ ton compared to one-ton base asphalt concrete. One ton of asphalt concrete is regarded as a unit in the process of computing additional cost as shown in Table 8 .

Value coefficient of each type of concrete is attained when performance promotion coefficient $F$ and additional cost $C$ are substituted into the evaluation model and the results are listed in Table 9. The value coefficient represents performance promotion relative degree of the mixture when $100 \mathrm{RMB} ¥$ is invested in modifying one ton of base asphalt concrete. Specific sequencing of each type of mixture is as follows: hybrid fiber (2.05) > polyester fiber (1.58) > PP fiber (1.55) $>$ lignin fiber (1.43). It shows that the cost-benefit of hybrid fiber is better than that of each single fiber from the above results.

\section{Conclusions}

This study is carried out to put forward a sample method to design hybrid fiber used in the asphalt concrete and verify engineering applicability and economic superiority of the hybrid fiber modified asphalt concrete. From the testing results and corresponding analysis, the following conclusions can be drawn:

(i) The experimental device DSD was developed to test the fiber modified asphalt samples' shear stress-strain curves. Based on this, shear damage energy density
(SDED) was proposed to evaluate shear resistance of asphalt samples. Experimental results prove that the SDED can distinguish the shear resistance of different hybrid fiber modified asphalt effectively. Therefore, direct shear test can be used to design the dosage of hybrid in asphalt and its components.

(ii) Range and variance analysis results revealed that the dosage of lignin fiber, polyester fiber, and PP fiber in the hybrid fiber shows significant impact on the SDED of hybrid fiber modified asphalt. The greatest influence factor is the PP fiber dosage, followed by the lignin fiber dosage and polyester fiber dosage. In order to obtain the maximum shear resistance, the optimum dosage of hybrid fiber in asphalt is $7.2 \%$ and the composition ratio of the three single fibers in hybrid fiber is $3: 4: 5$.

(iii) The laboratory results of the engineering performance suggested that hybrid fiber reinforced asphalt concrete has desirable high-temperature rutting resistance, low-temperature cracking resistance, and moisture susceptibility. Moreover, the engineering performance of the hybrid fiber modified asphalt concrete is more balanced compared to the three kinds of single fiber modified asphalt concrete, which indicates that the hybrid fiber gives full play to the modified advantage of the three kinds of single fibers and there exists combined effect in the hybrid fiber.

(iv) A cost-benefit model considering both performance and economy aspects was applied in this paper to compare the advantage of hybrid fiber, lignin fiber, polyester fiber, and PP fiber in engineering application. It is shown that the cost-benefit of hybrid fiber is better than each single fiber, which means that hybrid fiber is a good choice to reinforce asphalt concrete.

\section{Competing Interests}

The authors declare that they have no competing interests.

\section{Acknowledgments}

This research is supported by the funds of National Natural Science Foundation of China (NSFC) (no. 51478046) and the Special Fund for Basic Scientific Research of Central Colleges, Chang'an University (no. 310821150015). 


\section{References}

[1] M. D. I. Domingos and A. L. Faxina, "Susceptibility of asphalt binders to rutting: literature review," Journal of Materials in Civil Engineering, vol. 28, no. 2, Article ID 04015134, 8 pages, 2016.

[2] E. A. Oluwasola, M. R. Hainin, and M. M. A. Aziz, "Evaluation of rutting potential and skid resistance of hot mix asphalt incorporating electric arc furnace steel slag and copper mine tailing," Indian Journal of Engineering and Materials Sciences, vol. 22, no. 5, pp. 550-558, 2015.

[3] X. Guo, M. Sun, W. Dai, and S. Chen, "Performance characteristics of silane silica modified asphalt," Advances in Materials Science and Engineering, vol. 2016, Article ID 6731232, 7 pages, 2016.

[4] N. Gibson and X. J. Li, "Characterizing cracking of asphalt mixtures with fiber reinforcement use of cyclic fatigue and direct tension strength tests," Transportation Research Record, no. 2507 , pp. 57-66, 2015.

[5] M. Shukla, D. Tiwari, and K. Sitaramanjaneyulu, "Performance characteristics of fiber modified asphalt concrete mixes," International Journal on Pavement Engineering \& Asphalt Technology, vol. 15, no. 1, pp. 38-50, 2014.

[6] B. W. Guan, S. F. Chen, and R. Xiong, "Low temperature anti-cracking performance of brucite-fiber-reinforced asphalt concrete," Advanced Materials Research, vol. 228-229, pp. 23-28, 2011.

[7] F. Moghadas Nejad, M. Vadood, and S. Baeetabar, "Investigating the mechanical properties of carbon fibre-reinforced asphalt concrete," Road Materials and Pavement Design, vol. 15, no. 2, pp. 465-475, 2014.

[8] Q. Guo, L. Li, Y. Cheng, Y. Jiao, and C. Xu, "Laboratory evaluation on performance of diatomite and glass fiber compound modified asphalt mixture," Materials \& Design, vol. 66, pp. 5159, 2015.

[9] H. Wang, P. Liu, and L. J. Sun, "Characterization of OGFC mixtures containing lignin fibers," in Advanced Building Materials and Sustainable Architecture, vol. 174-177 of Applied Mechanics and Materials, pp. 775-781, 2012.

[10] Z. Hong and L. Liang, "Research on the performance of asphalt mixtures of polymer fibers," Applied Mechanics and Materials, vol. 505-506, pp. 228-233, 2014.

[11] R. Xiong, J. Fang, A. Xu, B. Guan, and Z. Liu, "Laboratory investigation on the brucite fiber reinforced asphalt binder and asphalt concrete," Construction and Building Materials, vol. 83, pp. 44-52, 2015.

[12] Q. Xue, X.-T. Feng, L. Liu, Y.-J. Chen, and X.-L. Liu, "Evaluation of pavement straw composite fiber on SMA pavement performances," Construction and Building Materials, vol. 41, pp. 834843, 2013.

[13] J. Wang, C. Li, X. Fan, and M. Zhang, "Flexural fatigue behavior of layered hybrid fiber reinforced concrete," Journal Wuhan University of Technology, vol. 22, no. 3, pp. 560-563, 2007.

[14] S. Wu, H. Yue, Q. Ye, and L. Pang, "Performances research of hybrid fiber reinforced asphalt concrete," in Proceedings of the 6th International Forum on Advanced Material Science and Technology (IFAMST '08), vol. 614, pp. 283-288, Hong Kong, June 2009.

[15] H. B. Yue and S. P. Wu, "Investigation of viscoelastic and fatigue properties of Hybrid Fiber Reinforced Sand Asphalt Mixture," in Proceedings of the Advances in Heterogeneous Material Mechanics-2nd International Conference on Heterogeneous
Material Mechanics (ICHMM '08), pp. 1061-1064, Huangshan, China, June 2008.

[16] S. M. Abtahi, S. Esfandiarpour, M. Kunt, S. M. Hejazi, and M. G. Ebrahimi, "Hybrid reinforcement of asphalt-concrete mixtures using glass and polypropylene fibers," Journal of Engineered Fibers and Fabrics, vol. 8, no. 2, pp. 25-35, 2013.

[17] M. Vadood, M. S. Johari, and A. Rahai, "Developing a hybrid artificial neural network-genetic algorithm model to predict resilient modulus of polypropylene/polyester fiber-reinforced asphalt concrete," The Journal of the Textile Institute, vol. 106, no. 11, pp. 1239-1250, 2015.

[18] Ministry of Transport of the Peoples Republic of China, Technical Specifications for Construction of Highway Asphalt Pavements JTG F40-2004, China Communication Press, Beijing, China, 2004.

[19] H. Chen, Q. Xu, S. Chen, and Z. Zhang, "Evaluation and design of fiber-reinforced asphalt mixtures," Materials \& Design, vol. 30, no. 7, pp. 2595-2603, 2009.

[20] A. Qadir, "Rutting performance of polypropylene modified asphalt concrete," International Journal of Civil Engineering, vol. 12, no. 3, pp. 304-312, 2014.

[21] Y. Yan, C. Cocconcelli, R. Roque et al., "Performance evaluation of alternative polymer-modified asphalt binders," Road Materials and Pavement Design, vol. 16, supplement 1, pp. 389-403, 2015.

[22] Ministry of Transport of the Peoples Republic of China, Standard Test Methods of Bitumen and Bituminous Mixtures for Highway Engineering JTG E20-2011, China Communication Press, Beijing, China, 2011. 

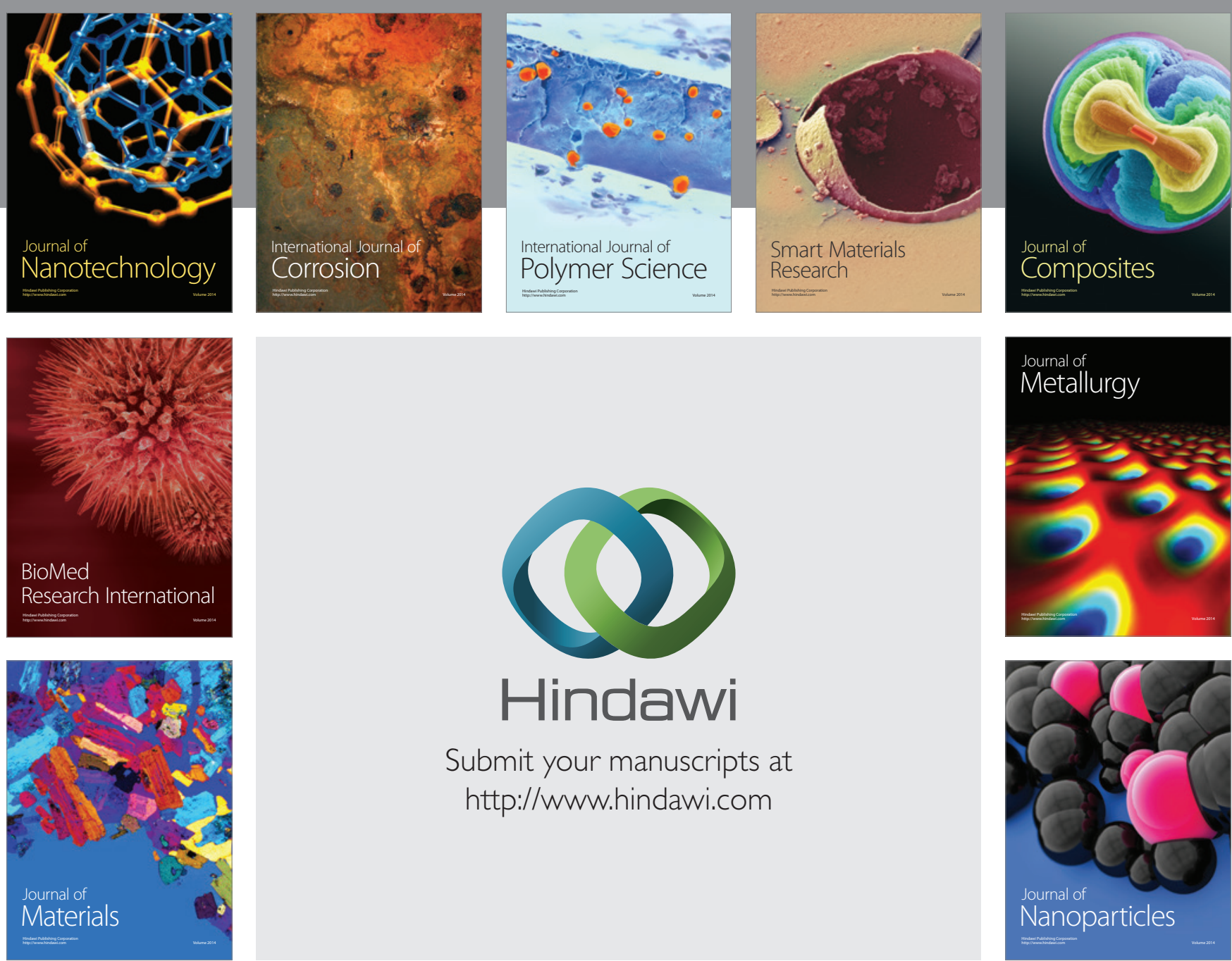

\section{Hindawi}

Submit your manuscripts at

http://www.hindawi.com

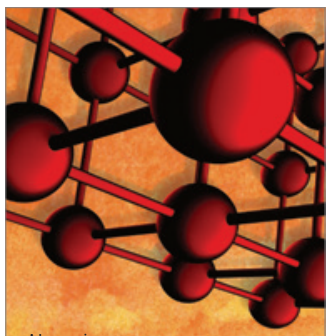

Materials Science and Engineering
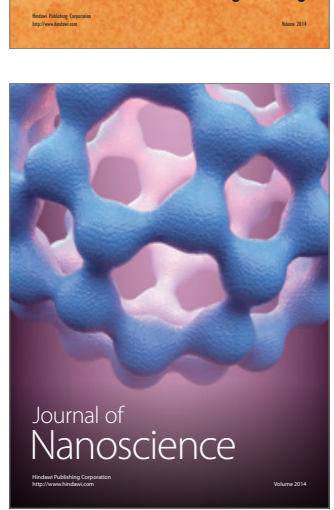
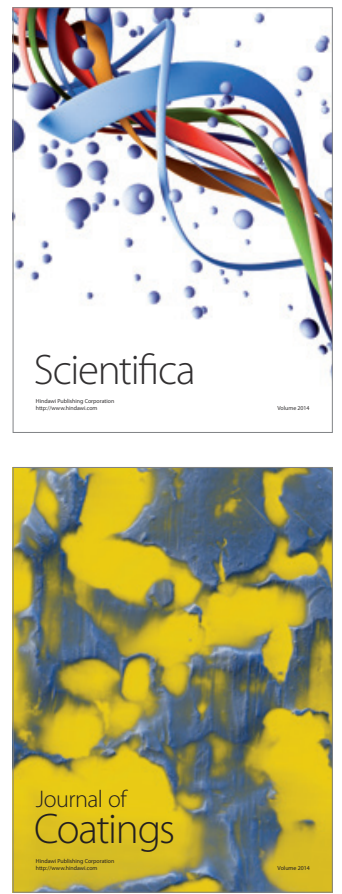
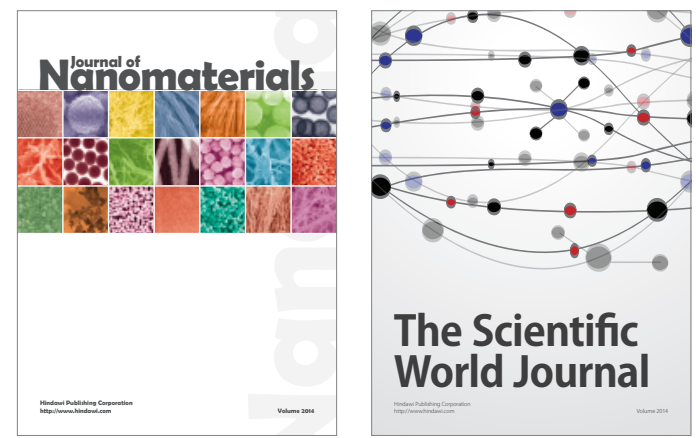

The Scientific World Journal
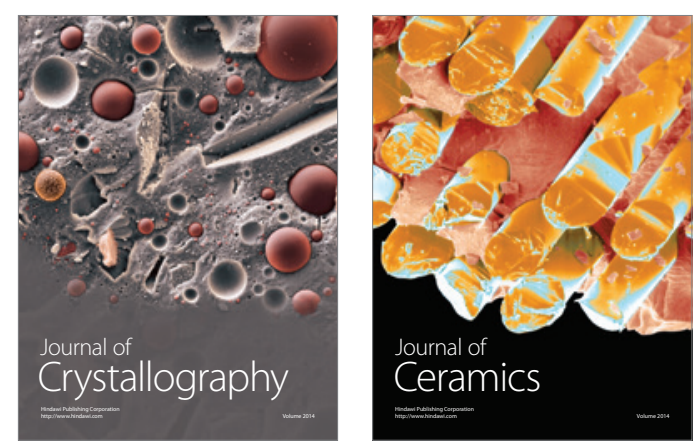
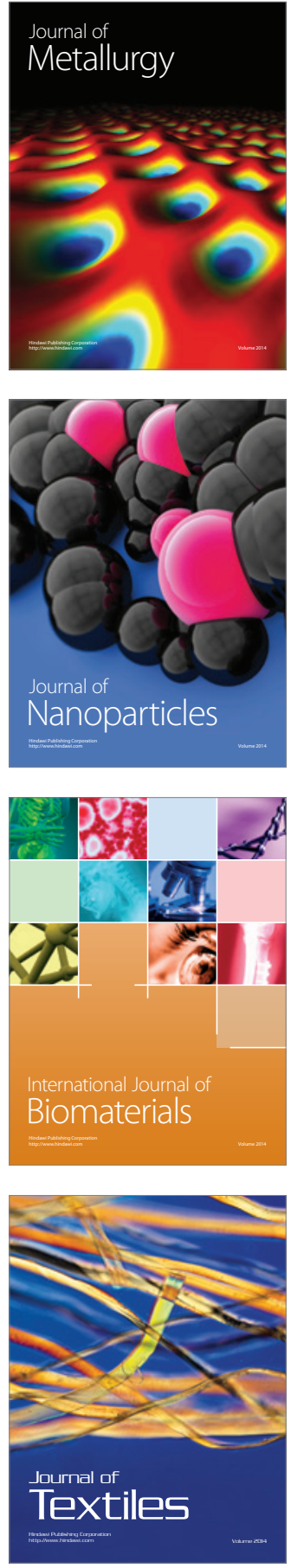